\title{
Mergers in higher education institutions: a proposal of a novel conceptual model
}

\author{
Lukasz Sułkowski \\ Institute of Public Affairs, Faculty of Management and Social Communication, \\ Jagiellonian University, Kraków, Poland \\ Justyna Fijałkowska \\ Department of Finance and Accounting, \\ University of Social Sciences, Warsaw, Poland, and \\ Małgorzata Dzimińska \\ University of Social Sciences, Warsaw, Poland
}

Mergers in

higher

education

institutions

Received 30 January 2018

Revised 17 July 2018 23 October 2018

Accepted 6 November 2018

\begin{abstract}
Purpose - The macroeconomic changes as well as the challenges facing universities nowadays result in the transfer and adaptation of various concepts and organizational methods from enterprises to universities. One of such solutions is mergers. Even though there are a very large number of practical examples of university mergers in the world, at the same time there is a shortage of frameworks that would help manage mergers. The purpose of this paper is to present key areas of focus in HEIs' consolidation processes and the creation of the conceptual model of the universities' mergers.

Design/methodology/approach - In this paper synthesis, the inductive approach for model development and case study description were used. The analysis and findings were based on the systematic literature review taken out from management and public policy areas. The new public management and public value governance approaches as well as strategic and process theories of mergers were applied. The descriptive approach to management was used as well.

Findings - Formulation of a Conceptual Model of Universities' Mergers and ten principles of effective management of universities' mergers that cover the entire process, from planning, through implementation, to integration.

Research limitations/implications - There is a need to verify the proposed inductive model of universities' mergers through further qualitative and mixed-methods research studies.

Practical implications - The paper offers a significant opportunity for practical application of the presented content, because it indicates how the know-how from one (business) sector can be valuable for the future of another sector (the over-fragmented sector of higher education).

Originality/value - This study presents the key areas of focus in HEIs' consolidation processes and proposes a novel Conceptual Model of Universities' Mergers. It concludes with the principles of effective management of universities' mergers.
\end{abstract}

Keywords Mergers, Strategic management, Universities, Higher education, Conceptual model,

Consolidation processes

Paper type Research paper

\section{Introduction}

In today's reality, characterized by increased cross-border competition in both educational services and research outputs, universities are under strong pressure to both compete and collaborate. Higher education institutions (HEIs) compete for financial resources, talented

(C) Lukasz Sułkowski, Justyna Fijałkowska and Małgorzata Dzimińska. Published by Emerald Publishing Limited. This article is published under the Creative Commons Attribution (CC BY 4.0) licence. Anyone may reproduce, distribute, translate and create derivative works of this article (for both commercial and non-commercial purposes), subject to full attribution to the original publication and authors. The full terms of this licence may be seen at http://creativecommons.org/licences/by/4.0/legalcode

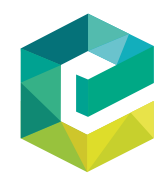

Managerial Finance Vol. 45 No. 10/11, 2019 pp. $1469-1487$ 
MF $45,10 / 11$

1470

students, high-quality lecturers, brilliant researches, good reputation and status, as well as high scores in international rankings. The increasingly competitive global market is the important driver of institutional mergers which become an important strategy of many HEIs. Other strategies, as underlined by Harman and Harman (2008, p. 99), include informal collaboration; joint business ventures; strategic alliances; regional, national and international networks and consortia; as well as cross-institutional mergers of academic and/or service departments. This study concentrates on strategic management of mergers in HEIs. The consolidation of universities is a major theoretical and practical challenge. However, despite a very large number of practical examples of university mergers worldwide, at the same time there is a shortage of frameworks that would help manage mergers in the HEIs context. This paper is an attempt to respond to these needs and grow the body of knowledge in this area.

One of the concepts giving the theoretical basis to the topic of strategic mergers of universities concerns the theory of social identity, other refer to strategic and process theories of mergers and acquisitions (M\&A) (Cai, 2006; Cartwright and Schoenberg, 2006; Gleibs et al., 2013). In the public sector, the basis for analyzing the concept of consolidation is the theories of "new public management" (NPM) and "public value management" (Bryson et al., 2017; Hartley et al., 2017). According to the trends of "new public management," university management can be treated as a complex process, similar to organizing the work of an enterprise (Dunleavy and Hood, 1994; Dunleavy et al., 2006). Mergers of public universities can illustrate the logic of this approach. Currently, in the process of university merger research, the higher education sector goes through the induction stage, where hundreds of case studies and a few comparative studies have been gathered that draw a complex picture of the mergers' practices and can serve as a source of guidance. However, there is a need for inductive synthesis of the sources of information and creation of a conceptual model that will help to guide the management processes.

The paper is organized as follows: Section 1 highlights context, reasons and strategic goals of mergers in HEIs. The following section refers to the areas of strategic focus during mergers. In Section 3, we present the proposal of the Conceptual Model of Universities' Mergers that is followed by an example of a merger that resulted in establishing the Université Grenoble Alpes. The study finishes with the conclusions and the proposal of ten principles of effective mergers' management at universities.

2. Mergers in higher education institutions - context, reasons and strategic goals Strategic mergers are formal combinations of two or more organizations into a single organization deliberately planned, so as to more effectively meet external challenges and opportunities (Harman and Harman, 2003). In relation to higher education, strategic mergers are described as strategies of "merging colleges for mutual growth" (Martin and Samels, 2002). In terms of getting two institutions together, the following terms are used: M\&A, consolidation processes, takeovers, fusions, buy-outs and marriage. Despite the fact that these terms should not always be treated as synonyms, they are often used interchangeably. In a merger, one company takes over another, including all assets and liabilities. In a consolidation, two or more companies merge to form one new, larger company. All of each company's assets and liabilities then become the property of the new organization. Mergers and consolidations are ways in which companies can merge, following essentially the same process; therefore in our study, we will use the terms "mergers" and "consolidation" in relation to universities' mergers interchangeably.

The diagnosis of trends concerning changes in higher education has been developed on the basis of many studies and is widely described in the literature on this topic. One significant, clear trend is toward the development of larger and stronger "producers" of 
educational services and research. Moreover, there are several tendencies observable in the HEIs sector that prejudge the strategic changes in universities:

(1) High and increasing diversity of universities; the educational sector consists of organizations that differ substantially in their founding structure, activity, quality, specialization and size.

(2) Internationalization resulting in the increasing mobility of students, researchers, programs and entire institutions.

(3) Privatization and commercialization of education on a global scale, where higher education becomes a service coming from the sphere of "private goods," and science is an intellectual product.

(4) The development of the "entrepreneurial university" model.

(5) The reduction of the state's participation in subsidizing or even co-financing universities.

New globally competitive higher education environment dictates strong incentives toward competition between institutions, but at the same time makes many of them decide to cooperate, following different types of partnerships: from a very informal cooperation between researchers, through alliances, consortia, affiliations and federations to full scale mergers.

In the case of HEIs, the implementation of the mergers' plans should lead to fulfillment of the mission and achievement of strategic goals related to the improvement of research and education or/and to the implementation of the universities' third mission (Di Berardino and Corsi, 2018; Zomer and Benneworth, 2011). In the second half of the twentieth century, there was a departure from the traditional formation of the Humboldtian university vs the entrepreneurial university (Clark, 1998). It is more and more visible that universities, especially those private ones, however also public HEIs, use economic logic and solutions developed in the field of business management. Competition, commercialization of research and cooperation with the socio-economic environment are becoming increasingly important. Internationalization and globalization of universities is growing, complex cooperation networks are being formed, and universities are competing for the best researchers and students through international cooperation. Universities begin to resemble business units and therefore they face similar competitive challenges. The university is transforming into an economic market organization that follows the concept of "new public management" (de Boer et al., 2007; Hood, 1995; Sulkowski, 2016).

Entrepreneurship tendencies in the university culture are reflected, inter alia, in the orientation on innovation, in scientific activities carried out in cooperation with the industry, in the application of organizational solutions of "quasi-business" and "quasi-corporate" type, as well as in the pursuit of generating revenues from educational and scientific activities. In addition, "entrepreneurial universities" implement a market mission and create competitive strategies, use accountability and governance methods, and make decisions using a managerial model (management and supervisory authorities have the power), not a collegiate one (based on an academic staff). Mergers may be treated as a manifestation of the development of entrepreneurial university formation and academic entrepreneurship, both in relation to public and private HEIs. Private universities, through merger and consolidation processes, develop economies of scale and improve organizational methods, which lead to more effective market operation and fulfillment of their mission (Rudden, 2010). Moreover, in private HEIs, e.g. in the USA, mergers have been commonly used by individual institutions to deal with threats of closure, declining enrollments or even bankruptcy (Harman and Harman, 2003). Public universities recognizing that there are too many too small institutions try to obtain through mergers a "critical mass" in scientific,
Mergers in higher education institutions 
$\mathrm{MF}$ $45,10 / 11$ educational and operational activities (Aula and Tienari, 2011; Tirronen and Nokkala, 2009). Generally, e.g. European universities are having hard time competing with their American counterparts, because they are relatively small and poorly funded. Lang (2003), while analyzing the reasons of mergers among public universities, underlines that governments want new programs at relatively low marginal costs. Moreover, mergers can reduce sunk costs of previous investments as the facilities may be utilized more efficiently. Some studies have confirmed also the financial drives of many mergers in HEIs (Eastman and Lang, 2001) pointing out that universities' mergers can result in significant economies of scale (Brinkman and Leslie, 1986; Lang, 2003; Lang, 2002; Sears, 1983).

Following Pinheiro et al. (2017) and Sułkowski (2017), it is possible to indicate several strategic goals, concerning universities' mergers:

(1) increase of the effectiveness and efficiency of the universities' operations (Pinheiro and Stensaker, 2014);

(2) limitation of the higher education system fragmentation (concentration);

(3) expansion of students' access to the education network;

(4) strengthening the autonomy, responsibility and accountability of the university;

(5) creation of larger universities, growing scale of scientific, educational and operational activities, gaining the economies of scale and "critical mass" (Aula and Tienari, 2011; Docampo, Egret and Cram, 2015; Tirronen and Nokkala, 2009);

(6) optimization of operating costs (Harman and Harman, 2003);

(7) strengthening the competitiveness of a particular university at the national level (Goedegebuure and Meek, 1994; Harman and Harman, 2003);

(8) support for university competitiveness at the international level (Harman and Meek, 2002);

(9) strengthening the competitiveness and visibility of the entire country and the national education system at the international level (Docampo et al., 2015);

(10) meeting the needs of different stakeholders, in particular students and employers in a more efficient way;

(11) implementation of an effective strategic management mechanisms;

(12) restructuring and rationalization of university management;

(13) change of the competitive model to oligopolistic or even monopolistic in the case of private universities;

(14) diversification of the educational offer; and

(15) market expansion (mainly in case of private universities).

All the stakeholders of consolidating universities could benefit from their successful merger as it means a stronger institution that is in a position to compete better in today's global economy and become more effective and efficient.

\section{Areas of strategic focus during mergers}

In consolidation processes, strategic management plays a key role (Pinheiro and Stensaker, 2014). First of all, the decision about a merger itself should be preceded by a strategic analysis of the organization and the environment, which is the premise for making the decision on the merger. There should be consultations with various stakeholders and due diligence groups. The strategic objectives of the merger, which will be the basis for the 
preparation of the strategic plan, should be set (planning stage). The adoption of the strategic plan for the merger is related to the transition to the process of strategic coordination (implementation stage). Strategic management at this stage consists of drawing conclusions from due diligence as well as participation in negotiations and conclusion of contracts. Institutionalization of the merger - in the form of signing agreements and validating the decisions taken on the consolidation of entities - closes the implementation stage and constitutes the transition to the integration stage. Strategic management at the integration stage is associated with (Sułkowski, 2017):

- supervising the correctness of the merger and implementing the strategic plan;

- corrections to the strategic plan related to unforeseen situations;

- strategic controlling of the merger process;

- managing the work of management teams and the integration team;

- coordination of central unit activities; and

- conflict resolution and organizational and public communication.

Undoubtedly, decisions on mergers belong to the strategic ones. They are complex management processes that require a long-term implementation plan, consistent with the strategic plan for the development of the entire organization. The degree of complexity and difficulty of running consolidation processes depends on the number of factors: institutional characteristics, the type of consolidation - if it is voluntary one or a compulsory (take-over), the profile of the HEIs involved, number of partners and cultural context, just to mention a few. The actual strategic success of the merger is not just the implementation of the university merger itself, but also the effects it brings. In order to achieve them, universities must consider and deal with several challenges of consolidation processes. In this paper, we indicate five areas of strategic focus during mergers: academic due diligence, appropriate selection of methods and tools in restructuring, project management during mergers, academic leadership, and finally university brand management and marketing activities of universities in the merger process.

\subsection{Academic due diligence}

Due diligence means in-depth analysis, examination and verification of previous information, thanks to which a potential buyer or merger partner can make an assessment (Sułkowski, 2017, p. 186). Such verification usually takes the form of a written document that presents the actual situation of the organization and pays special attention to current and future possible risks that may occur after the merger. The general characteristics of due diligence should meet the requirements of credibility, accountability, validity, accuracy, transparency, completeness and clarity. The scope of due diligence is wide, because this comprehensive analysis includes financial, legal, infrastructural, technological, organizational, intellectual resources, human resources and organizational culture analyses.

The due diligence in universities should focus on the most important goals, potential synergic effects of consolidated institutions as well as difficulties/barriers in the following areas:

- management (strategies, structures and organizational processes);

- material resources (campuses and laboratories);

- human resources (scientific and didactic staff, administration, students and graduates);

- financial resources (endowment, cash flow, costs and revenues);
Mergers in higher education institutions 
$\mathrm{MF}$ $45,10 / 11$
- intellectual and intangible assets (patents, intellectual rights, brand value and innovations); and

- cultural capital (culture and organizational identity).

The example criteria that may be audited via academic due diligence are indicated in Table I.

\subsection{Appropriate selection of methods and tools in restructuring}

Restructuring may be understood as a discontinuous (radical), violent and serious change (Reilly et al., 1993) or as the basic change in the organizational structure of the enterprise, its capital or assets (Bowman and Singh, 1990). The merger process is usually closely coupled with restructuring, because it is a radical transformation that provides the opportunity to conduct deep organizational changes. In principle, the merger is always accompanied by restructuring, which serves to rationalize the activities of the consolidated universities. Restructuring happens to be the initial stage of the merger; however, it may take longer than

\begin{tabular}{ll}
\hline Criteria & Scientific \\
\hline Previous effects & 1. Evaluation, \\
of universities & parameterization \\
planning the & 2. Rankings of scientific \\
merger & excellence \\
& 3. Outstanding achievements \\
& (e.g. Nobel Prizes)
\end{tabular}
4. Quality of scientific activity

People and teams of both universities

1. Outstanding personalities, talents and scientific leaders 2. Composition and potential of scientific teams

1. Outstanding

Programs

1.Scientific grants, projects and programs

Scientific and educational authorizations Synergy after the merger

Table I.

Academic due diligence criteria
1. The right to award academic degrees 2. Scientific certifications 1. Increase in quality and the amount of work 2. Promotion in rankings 3. Increase in the value or number of outstanding achievements

4. Larger number of outstanding researchers and teams

5. Greater number of grants, projects, certificates and programs 6. Better organization of the educational system
Educational

1. The value of graduates in the labor market 2. Prestige of the university the board of trustees, founders 3. Quality of education

(accreditations,

2. Cooperation with the society personalities and teaching talents

2. Composition and potential of educational teams

Implementational

1. Capital of connections and donors) innovations

4. Quality and scale of cooperation

1. Outstanding personalities, organizational and implementation talents 2. Composition and potential of implementation teams

1. Education programs

2. Range of the educational offer 3.Organization of education

1. Teaching qualifications

2. Certification and educational accreditation

1. Implementation of new programs

2. Organization of cooperation with the environment (e.g. career offices)

1. Practical authorizations 2. Industry certifications and accreditations

1. Increased employability 1 . Development of the capital and value of graduates 2. Increase in prestige 3. Improvement in the quality of education (new accreditations, certifications, rankings) of connections and cooperation with the environment

2. Increase in the number and and incubators

4. Expansion and increase 3. Larger number and value of of the value of the offer patents and implementations 4. Improvement in the system environment (stakeholders, composition of scale of innovations, spin-offs of cooperation with the 
the merger itself. In the case of public universities, restructuring is rarely the most important goal of a merger, but it is often implemented as a consequence of the consolidation process. In the mergers of private universities, restructuring is usually one of the key objectives, because the possibility of creating added value through the merger requires a deep reengineering of the whole institution. Identification of areas for restructuring takes place at the stage of analysis and strategies creation (due diligence). Such identification should lead to:

(1) analysis of organizational strategy, structure and culture;

(2) definition of measures and indicators, the measurement of the current status and planned targets (after merger and restructuring);

(3) choosing the methods of restructuring during the merger and after its implementation; and

(4) creation of a merger plan taking into account restructuring processes.

Depending on the area of change, three types of restructuring can be distinguished: operational, financial and concerning the ownership. Each of them focuses on different aspects that are presented in Table II.

The university restructuring methods used in the merger processes relate appropriately to all processes and functional areas of the organization, namely finance and accounting, as well as the management of: people, quality, information, marketing, infrastructure and other aspects of operations. The typology presented in Table III does not cover all restructuring methods, tools and approaches that can be applied at universities, but it constitutes a list of options to consider in the merger processes.

In the mergers of universities, various restructuring methods and techniques are used; however, as Sulkowski (2017, p. 206) indicates, there should not be introduced too many complex methods of university restructuring (e.g. reengineering, Six Sigma or lean management) simultaneously. Before planning the merger, it is necessary to reflect and select the appropriate mix of useful methods, techniques and tools to be used in organizational changes.

\subsection{Project management in university merger processes}

Mergers can be operationalized as inter-organizational projects that lead to the improvement of processes: research, education and cooperation with the environment. Mergers of universities refer to deliberate organizational change, with a framed plan, time restrictions and budget limits. Projects have become means of implementing the organizational changes in HEIs. Effective project management in universities results in an increased competitiveness and value. The composition of the projects involved in the merger may

Type of

restructuring

Description

Operational restructuring

Concerns changes in the core business of the enterprise and in the case of the university sector it may relate to, among others, marketing activities of the university, human resources (academic and non-academic staff), technological and property resources of the university, as well as the organization and management processes implemented at the university

Financial restructuring Ownership restructuring

Source: Authors' own study
Mergers in higher education institutions 
MF

$45,10 / 11$

1476
Table III.

\section{Examples of}

restructuring methods used in consolidation processes of HEIs
Aim Restructuring methods

Reengineering

Lean management

Kaizen

TQM and EFQM

ISO 9001

Six Sigma

Benchmarking

Shared service centers

Target costs

Rationalization of the scope of activities Strategic segmentation (basic, non-operational, auxiliary and maintenance functions)

Diversification

Outsourcing

Insourcing

Improvement of organizational forms Creating cost centers

creating profit centers

Creating strategic business units

Division of the organization and creation of independent entities

Selection of adequate structural solutions Divisional structure

design structure

Matrix structure

Holding

Improvement of the organizational

structure

Diagnosis of the organizational structure

Designing a streamlined organizational structure

Implementing changes in the structural solution

Improvement of the organizational culture Cultural audit

Cultural change programs

Source: Authors' own study

vary depending on the strategy and mission of the particular university. University mergers should lead to synergy that provides the opportunity to improve the core processes (Patterson, 1999). In the management process of a merger, a mix of various methods, tools and techniques listed in Table III can be applied. Apart from that a three-level typology of merger projects in HEIs can be built according to the parameters: project duration, range of changes, degree of complexity, project effects and scope of changes. The typology of the universities' merger projects is presented in Table IV.

\subsection{Academic leadership during the merger}

Leadership plays a key role during a merger process. Harman and Harman (2003, p. 29) state: "sensitivity to human and cultural factors and effective leadership are the most important factors for achieving success in university merger." Academic leadership is to encourage members of the organization to act together, leading to the realization of the goals of this institution. The concepts of academic leadership are derived from a rich theory, and are developed on the basis of organization and management, psychology and sociology. Effective leadership that is crucial for the success of the merger may be analyzed from the perspective of various theoretical schools. They embrace mainly: theory of attributes, situational theories, management style concepts, critical trend regarding the school of leadership, the school of neocharismatic and transformation leadership and the team management school. In the context of university mergers, there are four main concepts of leaders that seem to be the most relevant. Their main characteristics are described in Table V. 


\begin{tabular}{|c|c|c|c|c|c|c|c|}
\hline Type & $\begin{array}{l}\text { University merger as a } \\
\text { type of project }\end{array}$ & Time & $\begin{array}{l}\text { Range } \\
\text { of } \\
\text { changes }\end{array}$ & $\begin{array}{l}\text { Degree of } \\
\text { complexity }\end{array}$ & Project effects & $\begin{array}{l}\text { Range of } \\
\text { changes }\end{array}$ & $\begin{array}{r}\text { Mergers in } \\
\text { higher } \\
\text { education }\end{array}$ \\
\hline Strategic & \multirow{2}{*}{$\begin{array}{l}\text { 1. A comprehensive } \\
\text { university merger project } \\
2 \text {. Integration of } \\
\text { universities } \\
\text { 1. Implementation of a } \\
\text { new strategy } \\
\text { 2. Implementation of a } \\
\text { new name and logo } \\
\text { 3. Implementation of a } \\
\text { new IT system } \\
\text { 4. Implementation of a } \\
\text { new system of education } \\
\text { quality management } \\
\text { 5. Implementation of new } \\
\text { management systems for } \\
\text { human capital }\end{array}$} & $2-5$ years & Large & Large & $\begin{array}{l}\text { Impact on the } \\
\text { organization and } \\
\text { its environment }\end{array}$ & $\begin{array}{l}\text { Changing the } \\
\text { content of the } \\
\text { work (what) }\end{array}$ & institutions \\
\hline Tactical & & $1-2$ years & Medium & Medium & $\begin{array}{l}\text { Impact on most } \\
\text { elements of the } \\
\text { organization }\end{array}$ & $\begin{array}{l}\text { Changing the } \\
\text { way of work } \\
\text { (how) }\end{array}$ & \\
\hline Operational & $\begin{array}{l}\text { 1. Information campaign } \\
\text { 2. Adaptation of systems } \\
\text { at the level of } \\
\text { departments } \\
\text { 3. Training of } \\
\text { administrative staff } \\
\text { 4. Changes in job } \\
\text { descriptions }\end{array}$ & $\begin{array}{l}\text { Up to } 1 \\
\text { year }\end{array}$ & Small & Small & $\begin{array}{l}\text { Impact limited to } \\
\text { the unit under } \\
\text { which the project } \\
\text { was implemented }\end{array}$ & $\begin{array}{l}\text { Changing the } \\
\text { ways (by } \\
\text { whom, when } \\
\text { and where the } \\
\text { work is done) }\end{array}$ & $\begin{array}{r}\text { Table IV. } \\
\text { Typology of } \\
\text { university merger }\end{array}$ \\
\hline Source: Al & athors' own study & & & & & & \\
\hline
\end{tabular}

\subsection{University brand management and marketing activities of universities in mergers}

Building reputation through intensive communication, marketing and internal branding (employer branding) is gaining importance in the academic world. Branding and image are notions related to reputation, they are also associated with culture and organizational identity (Aula and Tienari, 2011). All these areas of the organization's activity are subject to profound transformations in the processes of a merger. During mergers, the universities must use the concepts of marketing communication, brand management and organizational identity. The international and national recognition of universities for students and other external stakeholders depends to high extent on the university brand. The name of the university creates its image by providing a message that reflects the identity of the university. It creates trust, loyalty and reputation of the institutions. More and more often, students who make the decision about choosing a university take into account the value of the brand, e.g. the benefits that may result from receiving a graduation diploma from that particular institution. Following Aaker (1991), while verifying the value of the university brand, five basic elements described in Table VI should be considered.

The search for sophisticated concepts and marketing tools by universities is increasingly noticeable in order to build an appropriate brand image of the university and to attract customers, especially during or after merger. However, the marketing activities of universities concerning mergers are not limited to brand management. Contemporary marketing activities at universities focus not only on the regular promotion of the educational offer, but also on relational activities - building the image of the university. Especially, the concept of relationship marketing that has been transferred from other market sectors has become very popular among professionals performing marketing activities at universities (e.g. Plewa et al., 2005). 
$\mathrm{MF}$ $45,10 / 11$

\section{8}

Table V.

Concepts of leaders in university merger

$\begin{array}{lll}\text { Theory Description } & \text { Strong and weak points }\end{array}$

Transformational The leader sets the direction of change and and neocharismatic allows for quick, efficient and effective leadership operations. This approach is based on the mutual trust of the leader and team members. It is also based on values and shaping of collective and individual identities. The leader focuses on transforming the perception and interpretation of reality (sensemaking and sensegiving), which allows the group to believe in the sense and value of the change that is taking place

Situational school of The basis of research in this approach is leadership searching for the conditions of effective leadership in university mergers processes that is affected by a particular situation/ conditions. It means that each case is to be analyzed on an individual basis

There is a threat concerning the creation of illusions and mistakes. Therefore, the perspective of transformational leadership should be balanced; its task is to combine a positive attitude to change with a pragmatic view of the process implementation

The benchmarks are precious. In the literature on the subject of university mergers, case studies are the most numerous, although at the same time there is no comparative analysis. In the induction process, large number of data on effective leadership is gathered, however it is still difficult to build a universal theory now

Team leadership

Team leadership in complex organizations Not always it is possible to build a such as universities plays a key role. Effective team that meets all the requirements mergers of universities can only be carried out of an effective and efficient by committed, competent and flexible employee teams. The role of leaders is important because it involves making cooperation. Behavioral aspects make crucial role in the works of teams strategic decisions; however, with a significantly high level of organizational complexity of merger processes, the codecision makers are mostly team members. Team leadership focuses on self-learning teams that by cooperating with each other and with external entities develop a consolidation project

Critical perspective The processes of mergers at universities of leadership create changes that may have a negative impact on the objectivity of leaders. They may fall into the traps of autocracy, narcissism, oppressive treatment of employees, manipulation of people and treating the scientific and educational mission as a smokescreen

Critical analysis allows leaders to combine ethical solutions with pragmatism necessary to implement organizational changes (Aasen and Stensaker, 2007)

Source: Authors' own study

\section{The Conceptual Model of Universities' Mergers}

The systematic literature review summarized in the previous sections provided an input to form a map of the concepts related to mergers in the higher education sector, thus allowing us to formulate a conceptual model, which essentially represents an "integrated" way of looking at the topic of universities' mergers (Liehr and Smith, 1999). Miles and Huberman (1994) defined a conceptual model as a visual or written product, one that "explains, either graphically or in narrative form, the main things to be studied - the key factors, concepts, or variables - and the presumed relationships among them" (p. 18). The proposed Conceptual Model of Universities' Mergers is an attempt to build a simplified representation of the 
Elements

Relationships with the brand

Other assets related to the brand

Loyalty

Brand awareness

Perceived value of the brand

Source: Authors' own study based on Aaker (1991)

Description university's brand
The reactions related to the association of the brand against the background of other brands are analyzed. Universities create relationships with graduates, students, employees and stakeholders, which leads to strengthening the

These are added features that the brand offers, for example certificates, accreditations, signed cooperation agreements. The name, logo and brand are strengthened by accreditations and certificates

It is manifested in the attachment to the university of students and employees that shape ties with the university. Increasing number of universities implement loyalty programs among students and graduates

It involves: brand recognition, the number of associations with a given brand (in case of universities, these may embrace features like: very good quality of education, a recognized diploma in the labor market, good study conditions, qualified scientific and teaching staff), but also for example a well-known sports team

The perception of the university as an institution that offers products and services of a corresponding quality is measured. Very often, the perception of the quality of education at a given university is a determinant of choosing this particular institution
Mergers in higher education institutions

\section{9}

Table VI.

Elements of the Aaker model modified for the universities brandperception from the client's point of view

universities' mergers-related phenomena, providing useful basis for further exploration and understanding of the concepts and their interplay. The creation of the model was through inductive process where different concepts were researched and put together to form an integrated bigger map of the phenomena and their possible relationships. The model is an end result of bringing together the related researched concepts to give a broader understanding of universities' mergers. Figure 1 presents the proposal of the Conceptual Model of Universities' Mergers.

The Conceptual Model of Universities' Mergers presented in Figure 1 assumes that mergers between universities, just like in business, do not easily succumb to managerial control and project management, which enable full implementation of the objectives.

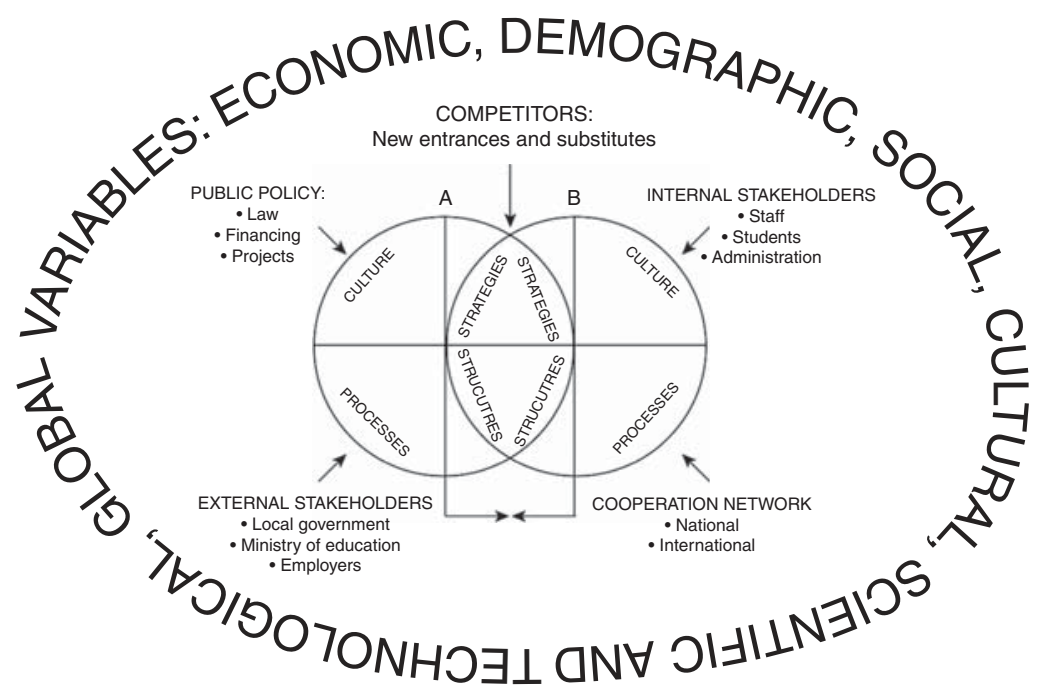

Source: Authors' own work

Figure 1. The Conceptual Model of Universities' Mergers 
MF $45,10 / 11$

\section{0}

The effectiveness of the implementation of mergers between universities is conditioned by a number of supporting and inhibiting factors.

Supporting factors include:

- relative homogeneity of the merging organizations (similar type of activity, similar founding or ownership structure);

- origin of the merging organizations (lack of far-reaching cultural and legal differences if the universities come from one country); and

- benefits of mergers that may occur for the institutions involved.

Inhibiting factors include:

- conservatism of traditional academic cultures;

- a strong ethos of academic professions often oriented toward maintaining the status quo; and

- the dominance of the stakeholder model favoring the maintenance of compromise between groups of influence.

The merger process takes place at three levels:

- Level I: change of university organization systems. The merging universities integrate or/and restructure their organizational systems. Strategic areas, structures and processes as well as cultural aspects of the merged organizations require alignment.

- Level II: influence of the closer environment on the merger's process. The dynamics of the consolidation process are directly impacted by:

- competitors present in the country and in the world or new emerging competitors and institutions trying to fill the market niche by offering alternative educational offers;

- cooperation networks consisting of national and international entities cooperating with universities;

- internal stakeholders, i.e. academic staff, students and university administration;

- external stakeholders, i.e. ministries, central and local government, employers; and

- public policy, reflected in law, financing of universities and central and local programs.

- Level III: influence of the further environment on the merger's process. In this respect, the significance of the following key variables needs to be taken into account:

- Economic factors, such as: living standards and unemployment rate. They have a significant impact on the motivation to start a merger. One can risk a statement that the deterioration of the country's economic situation should become a catalyst for a wave of mergers, especially in dispersed higher education systems.

- Demographic variables related to fertility and the flow of human capital. They form the basis for assessing the demand for higher education at the national level.

- Social factors related to the level and structure of scholarisation in a given country. Social patterns have a significant impact on decisions if to study and what educational direction to choose. It is wherein worth mentioning that the transformation from an elite to an egalitarian higher education system is becoming a global megatrend. The waves of systemic mergers, carried out, among others, in China, EU countries and the USA in the 1990s, were designed to better adapt to the mass and even universal model of education (Mao et al., 2009).

- Cultural context that has a significant impact on consolidation processes, although the assessment of its impact is very difficult. Culture not only shapes the organizations themselves and the behavior of people in organizations, but also affects the 
functioning of the entire education system and even the dynamics of the consolidation process. In countries with a high level of social capital, with developed civic culture, university mergers have a greater chance of success, although there are also examples that contradict this thesis. Successful centralist mergers in China prove that even in a society with a relatively low civic culture, it is possible to effectively implement university consolidation (Cai and Yang, 2016, pp. 71-85). On the other hand, some unsuccessful mergers in the UK and Australia prove that culture is only one of the variables in the complex mosaic of influence factors (Martin, 1994, pp. 83-91).

- Scientific and technological environment: it is connected with the development of science requiring the reorganization of research units. The general tendency is to group together scientific units, which leads to the creation of a "critical mass" that allows to implement ambitious research projects and to develop renown scientific schools. New technologies emerge in the cooperation of the university with the industry and through the creation of spin-offs. New communication and network technologies also have a direct impact on conducting research (e.g. methods and laboratories) and education (e.g. on-line and distant education were motivational factors when merging even faraway campuses and schools).

- Global variables related to the internationalization of science and higher education and the development of global competition. One of the key mechanisms to drive the wave of strategic mergers in the public university sector that is sweeping through the world is global rankings. The globalization is dominated by the English-speaking countries due to the international role of English and the scientific and educational position of universities. In many countries, mergers are carried out to promote the internationalization of universities by: opening joint, dual and double degree programs, as well as English-language programs, attracting foreign students and strengthening their academic exchange.

The growing numbers of publications, research and cooperation projects convince that mergers may lead to the implementation of many strategic goals and may affect both private and public universities. The proposed Conceptual Model of Universities' Mergers sheds some more light on this complex phenomenon. Understanding the context for the universities' mergers, realizing supporting and hindering factors, processes, structures and variables playing roles in the whole process can help plan future mergers more effectively.

\section{The use of the conceptual model: a case of the Université Grenoble Alpes}

The proposed Conceptual Model of Universities' Mergers can constitute a useful framework for analysis of the merger that resulted on January 1, 2016 in reuniting of three universities in France: Joseph Fourier University, Pierre Mendès-France University and Stendhal University, forming the Universite Grenoble Alpes. The split was made in 1970s and the XXI brought a strategic decision to reunite the three from four institutions that previously constituted the University of Grenoble (except from Polytechnic Institute of Grenoble). Table I presents the key elements of the proposed model and its relevance to the merger of the three universities in Grenoble. The data for the description of the Universite Grenoble Alpes were collected from May 2016 till mid-2017 in France through observations, interviews and collection of documents. The follow-up study visit to Grenoble was organized in May 2017 (Table VII).

In summary, the Universite Grenoble Alpes currently educates over 45,000 students and employs 5,500 employees in over 80 organizational units. The merger brought first results in the form of: intensification of scientific activities, improvement of organizational and managerial efficiency and generation of savings from consolidated processes and structures. Much effort was required from the employees to adapt to the new situation, which means that the results of scientific and educational activities should improve year by year. The interviews indicated 
$\mathrm{MF}$

$45,10 / 11$

\section{2}

Inhibiting factors

Change of university organization systems

Strategies

Structures

Processes

Table VII.

The application of the conceptual model of universities' mergers: case study of the Université Grenoble Alpes
The Université Grenoble Alpes case study

Homogeneity of the merging institutions stemming from the facts that they are all French Universities, are located in Grenoble and have a common history The involvement of employees in the merger was quite high due to the "Shanghai shock" which became a stimulus for change

The opportunity to use central financial programs to co-finance the merger The sense of creating a valuable and to some extent pioneering organizational solution in France

The merger date was announced early (in 2009) giving enough time for planning and preparation (until January 2016)

Groups disturbed by the merger were formed

Conservative attitude towards the merger was adapted by trade unions Attachment to the organizational structures and cultures of the separate universities was high

Elevated ambitions of the decision makers representing the merging universities were exhibited

As a result of strategic analyses, due diligence, research and negotiations, the following were agreed: the strategy and stages of the merger, the structure of the consolidated university, the new name and the authorities of the consolidated university

In the restructuring process, a new strategy was created which was focused on cooperation with the society, innovation as well as internationalization and development of high-quality research and education within a comprehensive university. The mission underlined the growing role of international interdependence, innovation and interdisciplinary research. It also confirmed that the heart of the university's activity was the combination of education and research The university's rector was chosen (Lise Dumasy, the rector of Université Stendhal for three tenures) as well as Vice-rectors who represented the merging universities New organizational structure was created. In total, 24 units such as departments, schools and institutes were distinguished in the organizational structure after consolidation. As part of the matrix structure, 6 large disciplinary research units were established

The university developed also a number of major improvement projects, which in turn led to a faster development of research. EQUIPEX enabled furnishing of laboratories in order to allow to undertake the most innovative research. IDEFI focused on the innovative education of students and researchers. LABEX allowed to establish and develop scientific cooperation with the best world centers and researchers. Infrastructure was also being developed, using public-private partnerships. A center of creativity and innovation was built to serve interdisciplinary research and education focused on innovation. Other examples were the health education and research center as well as the buildings of the law and social sciences departments

Deeper structural changes were introduced also in university-wide service units that cover various functional areas, such as finance and accounting, human resources, international cooperation, education and university life, research and innovation, information systems, logistics, cooperation with the environment and others The merger was preceded not only by a long period of close and formalized cooperation, but also by a six-year planning and preparation process for merger implementation at the strategic and operational level In the consolidation process, a new information system was implemented, covering not only the university management, but also the entire scientific output of employees and units, international relations and education quality management. New websites for the university and all units were also created, which was coupled 
The Conceptual Model of Universities' Mergers elements The Université Grenoble Alpes case study

with marketing activities, oriented towards the internet and social networking sites

Culture

Influence of the closer environment on the merger's process

Competitors

Cooperation network

Internal stakeholders in particular

A deepened specialization between research and teaching staff was introduced. Evaluation and remuneration and development systems rewarding higher productivity (performance based systems) were introduced. The positions, salaries and development opportunities of employees from different disciplines were differentiated. New branding and new identity were gradually being developed A wide consultation process was carried out, followed by communication, both among employees as well as students and other stakeholder groups

Each merging university had different focus in their areas of studies so they saw themselves as complementary rather than competitive entities. The merger was seen as strengthening of all universities by creating an entity that could become a stronger regional, national and international player and competitor

The merger of the universities into the Universite Grenoble Alpes offered a new path that other entities and cooperation networks started considering as a strategic option The staff participated in the preparation of the merger through systematic meetings in the framework of inter-university integration teams for several years The Polytechnic Institute of Grenoble, although initially discussed the merger, retreated in the course, mainly due to social resistance. The Polytechnic staff did not know if the merger would bring them sufficient benefits to compensate for the partial loss of independence

External stakeholders Negotiation and integration teams were established where representatives of all universities as well as central and local authorities and external stakeholders participated

Public policy The ministry and local authorities favored consolidation and actively supported it. The merger required some specific laws and regulations that were prepared. The merger process was co-financed under the Ministry's programs

Influence of the further environment on the merger's process

Economic

Demographic

Social

Cultural

Scientific and technological

Global
The conviction that the merger can lead to higher economic rationality and efficiency

There was an opinion that merger offers new developmental opportunities for employees. At the same time there was a fear for human resources reduction. The fact that the merging universities were complimentary in the areas of study limited the lay-offs scope

The concept of creating the Université Grenoble Alpes involved the assumption that also other universities from the Rhone-Alpes region can be involved in the merger. The discussions were held, however, in the end no more than the three institutions decided to participate in the consolidation process. The public entities, authorities at local and national levels as well as employers saw the merger as an opportunities-generating undertaking for the region. New entity was expected to be followed by the creation of new identity among the stakeholders

Merger was perceived as a mixture of opportunities and threats. New branding contributed to developing new identity of the institution and its stakeholders One of the consolidation motifs in France was to build strong links between universities and enterprises, which was supposed to fuel economic, scientific and technological development. There was an expectation that Grenoble merger could result in the "Silicon Valley" type of solution

The beginning of the 21st century in France brought "Shanghai shock," which was associated with the poor positions of French universities in international rankings. Achieving the "critical mass" in science through merger was to be a springboard to becoming a world-class academic institution with high international recognition
Mergers in higher education institutions 
MF $45,10 / 11$

1484

improvement of consolidated university management through: more effective strategic management, real emphasis on international cooperation and cooperation with the society, effective marketing communication and more advanced financial management and accounting. Employees mention faster and more efficient operation of administrative units compared to the situation before the merger. UGA implements mechanisms that dynamize scientific activity, which has improved its position in national and international rankings in the last two years. There is also a gradual increase in the number of English-speaking students and programs, which favors the internationalization of the university. The UGA educational offer was expanded, and at the same time unified and modernized.

\subsection{Summary}

Merger processes have produced positive results in many countries in the form of: increased effectiveness in conducting research (obtained grants, publications and implementations), higher recognition of universities (positions in international rankings) or optimization of the universities activity costs. At the same time, some negative effects of mergers may appear. They may be related to lower than expected effectiveness, resistance of the academic community, increase in the degree of universities bureaucratization and the weakening of academic culture. Moreover, frequently, consolidation processes do not fully achieve their goals, many of merger attempts finish as failures. The conclusion is that consolidations between universities can give positive results; however, the merger process should be effectively managed.

Based on the analysis of the literature and observations gathered during the case study data gathering the following ten principles of effective management of the universities' mergers may be proposed:

(1) analysis of the potential synergy effect and complementarity of the university in line with the properly conducted due diligence process;

(2) verification whether the merging organizations match in their identity and whether the change will bring status benefits;

(3) flexible and data-based analysis and strategic planning of the consolidation process, including controlling ("milestones," operational plans);

(4) communication and commitment of the main merger stakeholders who should be aware of potential benefits;

(5) taking into account the influence of culture and human capital management, enabling the satisfaction of the staff, students and other stakeholders from the consolidation process;

(6) transformational leadership that implements change and emphasizes benefits as well as identity change;

(7) effective management of the brand, PR and marketing communication processes, both inside and outside the organization;

(8) implementation of restructuring processes of consolidation project management methods, structural changes and the use of management concepts, experiments and research on the consolidation of universities;

(9) consideration of key areas of transformation, including systems: strategy, people management, IT, marketing, as well as research and education-related processes at all stages of implemented changes; and

(10) development of the vision and concept of an entrepreneurial, flexible, innovative and competitive university. 
These principles cover the entire process of a merger: from planning, through implementation, to integration. The proper application of these ten principles might contribute to more effective management of university mergers and a greater success of institutions that decide to take this strategic decision.

The proposed Conceptual Model of Universities' Mergers offers a framework for better understanding of the merger context and its variables. However, it is also important to mention the limitations related to the wider applicability of the model. Mergers belong to complex organizational processes. They constitute a radical change which the entire organization is subjected to in a relatively short time. The processes accompanying mergers are multidimensional and entangled in cultural and social factors that cannot be fully controlled causing that the trajectory of revolutionary cultural change happening in universities becomes partly indeterministic. Therefore, the created model needs to be viewed with these limitations in mind.

\section{References}

Aaker, D. (1991), Managing Brand Equity: Capitalizing on the Value of a Brand Name, The Free Press, New York, NY, p. 28.

Aasen, P. and Stensaker, B. (2007), "Balancing trust and technocracy? Leadership training in higher education", International Journal of Educational Management, Vol. 21 No. 5, pp. 371-383, available at: https://doi.org/10.1108/09513540710760165

Aula, H.-M. and Tienari, J. (2011), "Critical perspectives on international business becoming "worldclass' reputation-building in a university merger article information", Critical Perspectives on International Business, Vol. 7 No. 1, pp. 7-29, available at: https://doi.org/10.1108/ 09513550610669176

Bowman, E. and Singh, H. (1990), Overview of Corporate Restructuring: Trends and Consequences, McGraw-Hill, New York, NY.

Brinkman, P. and Leslie, L. (1986), "Economies of scale in higher education: sixty years of research", The Review of Higher Education, Vol. 10 No. 1, pp. 1-28, available at: https://muse.jhu.edu/article/ 645243/summary

Bryson, J., Sancino, A., Benington, J. and Sørensen, E. (2017), "Towards a multi-actor theory of public value co-creation”, Public Management Review, Vol. 19 No. 5, pp. 640-654, available at: https://doi.org/ 10.1080/14719037.2016.1192164

Cai, Y. (2006), "A case study of academic staff integration in a post-merger Chinese university", Tertiary Education and Management, Vol. 12 No. 3, pp. 215-226, available at: https://doi.org/ $10.1080 / 13583883.2006 .9967169$

Cai, Y. and Yang, X. (2016), "Mergers in Chinese higher education: lessons for studies in a global context", European Journal of Higher Education, Vol. 6 No. 1, pp. 71-85, available at: www.tandfonline.com/doi/ abs/10.1080/21568235.2015.1099458

Cartwright, S. and Schoenberg, R. (2006), "Thirty years of mergers and acquisitions research: recent advances and future opportunities”, British Journal of Management, Vol. 17 No. S1, pp. S1-S5, available at: https://doi.org/10.1111/j.1467-8551.2006.00475.x

Clark, B. (1998), "Creating entrepreneurial universities: organizational pathways of transformation", Issues in Higher Education, Bingley.

de Boer, H., Enders, J. and Schimank, U. (2007), "On the way towards new public management? The governance of university systems in England, the Netherlands, Austria, and Germany”, in Jansen, D. (Ed.), New Forms of Governance in Research Organizations, Springer, Dordrecht.

Di Berardino, D. and Corsi, C. (2018), "A quality evaluation approach to disclosing third mission activities and intellectual capital in Italian universities", Journal of Intellectual Capital, Vol. 19 No. 1, pp. 178-201, available at: https://doi.org/10.1108/JIC-02-2017-0042
Mergers in higher education institutions 
MF $45,10 / 11$
Docampo, D., Egret, D. and Cram, L. (2015), "The effect of university mergers on the Shanghai ranking", Scientometrics, Vol. 104 No. 1, pp. 175-191, available at: https://doi.org/10.1007/ s11192-015-1587-5

Dunleavy, P. and Hood, C. (1994), "From old public administration to new public management", Public Money \& Management, Vol. 14 No. 3, pp. 9-16, available at: https://doi.org/10.1080/ 09540969409387823

Dunleavy, P., Margetts, H., Bastow, S. and Tinkler, J. (2006), "New public management is dead - long live digital-era governance", Journal of Public Administration Research and Theory, Vol. 16 No. 3, pp. 467-494, available at: https://doi.org/10.1093/jopart/mui057

Eastman, J. and Lang, D. (2001), "Mergers in higher education: lessons from theory and experience", available at: $w w w . g o o g l e . c o m / b o o k s ? h l=e n \& l r=\& i d=F \_y D M B I 7 W z A C \& o i=f n d \& p g=P R 11 \&$ $\mathrm{dq}=$ Mergers+in + Higher + Education:+Lessons + from + Theory+and+Experience\&ots $=$ zYXpGsNHuG\&sig=qym336ApkON-81QYtBWRjzBv14w (accessed July 23, 2018).

Gleibs, I.H., Täuber, S., Tendayi Viki, G. and Giessner, S.R. (2013), "When what we get is not what we want: the roles of implemented versus desired merger patterns in support for mergers", Social Psychology, Vol. 44 No. 3, pp. 177-190, available at: https://doi.org/10.1027/1864-9335/a000102

Goedegebuure, L. and Meek, V. (1994), "A resource dependence perspective on mergers: comparing institutional amalgamations in Australia and the Netherlands", in Goedegebuure, L. and van Vught, F. (Eds), Comparative Policy Studies in Higher Education, LEMMA, Utrecht, pp. 127-164, available at: www.narcis.nl/publication/RecordID/oairis.utwente.nl:publications\%2F9a4884eb3c64-4bf3-b9c6-be262b497c8d

Harman, G. and Harman, K. (2003), "Institutional mergers in higher education: lessons from international experience", Tertiary Education and Management, Vol. 9 No. 1, pp. 29-44, available at: https://doi.org/10.1080/13583883.2003.9967091

Harman, G. and Harman, K. (2008), "Strategic mergers of strong institutions to enhance competitive advantage", Higher Education Policy, Vol. 21 No. 1, pp. 99-121.

Harman, K. and Meek, V. (2002), "Introduction to special issue: "merger revisited: international perspectives on mergers in higher education', Higher Education, Vol. 44 No. 1, pp. 1-4, available at: https://idp.springer.com/authorize/casa?redirect_uri=https://ink.springer.com/content/pdf/10.102 3/A:1015598525413.pdf\&casa_token=puTj4JFvHcwAAAAA:dTkzSu517uppTr_JuQhPeLekvLAu LMPJmrqE75qfTv0iDRcTqQn2L7qz_AM9V1oeHD7vYWZS-HZ8X4U

Hartley, J., Alford, J., Knies, E. and Douglas, S. (2017), "Towards an empirical research agenda for public value theory”, Public Management Review, Vol. 19 No. 5, pp. 670-685, available at: https:// doi.org/10.1080/14719037.2016.1192166

Hood, C. (1995), "The 'new public management' in the 1980s: variations on a theme", Accounting, Organizations and Society, Vol. 20 Nos 2-3, pp. 93-109, available at: https:/pdfs.semanticscholar.org/ 2807/1401574fd01fb00345dcba852f216a825e37.pdf

Lang, D. (2002), “A lexicon of inter-institutional cooperation”, Higher Education, Vol. 44 No. 1, pp. 153-183.

Lang, D. (2003), "The future of merger: what do we want mergers to do - efficiency or diversity?", The Canadian Journal of Higher Education, Vol. 33 No. 3, pp. 19-46, available at: https://eric.ed.gov/ ?id=EJ788478

Liehr, P. and Smith, M.J. (1999), "Middle range theory: spinning research and practice to create knowledge for the new millennium", Advances in Nursing Science, Vol. 21 No. 4, pp. 81-91.

Mao, Y., Du, Y. and Liu, J. (2009), "The effects of university mergers in China since 1990s”, International Journal of Educational Management, Vol. 23 No. 1, pp. 19-33, available at: https://doi.org/10.1108/ 09513540910926402

Martin, J. (1994), "Merging colleges for mutual growth. a new strategy for academic managers", available at: https://eric.ed.gov/?id=ED367242 (accessed July 23, 2018).

Martin, J. and Samels, J. (2002), "We were wrong; try partnerships, not mergers", The Chronicle of Higher Education, Vol. 48 No. 36, p. B10, available at: http://theunbrokenwindow.com/HigherEd/ FORPROFITS-GROUP1/partnerships, notmergers.doc 
Miles, M.B. and Huberman, A.M. (1994), Qualitative Data Analysis: An Expanded Sourcebook, Sage Publications.

Patterson, G. (1999), "The learning university", The Learning Organization, Vol. 6 No. 1, pp. 9-17, available at: https://doi.org/10.1108/09696479910255675

Pinheiro, R. and Stensaker, B. (2014), "Designing the entrepreneurial university: the interpretation of a global idea”, Public Organization Review, Vol. 14 No. 4, pp. 497-516, available at: https://doi.org/ 10.1007/s11115-013-0241-Z

Mergers in higher education institutions

Pinheiro, R., Aarrevaara, T., Berg, L., Geschind, L. and Torjesen, D. (2017), "Mergers and acquisitions in practice", in Tarba, S., Cooper, R. and Sarala, C. (Eds), Mergers and Acquisitions in Practice, Routledge, New York, NY, pp. 44-68, available at: https://doi.org/10.4324/9781315766140-10

Plewa, C., Quester, P. and Baaken, T. (2005), "Relationship marketing and university-industry linkages: a conceptual framework", Marketing Theory, Vol. 5 No. 4, pp. 433-456, available at: https://doi.org/ 10.1177/1470593105058824

Reilly, A.H., Brett, J.M. and Stroh, L.K. (1993), “The impact of corporate turbulence on: managers' attitudes", Strategic Management Journal, Vol. 14 No. S1, pp. 167-179, available at: https:// doi.org/10.1002/smj.4250140913

Rudden, M.S. (2010), "Five recession-driven strategies for planning and managing campus facilities", Planning for Higher Education, Vol. 39 No. 1, pp. 5-18, available at: www.learntechlib.org/ $\mathrm{p} / 109533 /$

Sears, K. (1983), "Economies of scale in higher education”, in Goodlad, S. (Ed.), Economies of Scale in Higher Education, Society for Research in Higher Education, Guildford.

Sułkowski, Ł. (2016), Kultura akademicka: koniec utopii?, Wydawnictwo Naukowe PWN, Warszawa.

Sułkowski, . (2017), "Fuzje uczelni: czy w szaleństwie jest metoda?”, available at: https:/ruj.uj.edu.pl/x mlui/handle/item/52117 (accessed July 23, 2018).

Tirronen, J. and Nokkala, T. (2009), "Structural development of Finnish universities: achieving competitiveness and academic excellence", Higher Education Quarterly, Vol. 63 No. 3, pp. 219-236, available at: https://doi.org/10.1111/j.1468-2273.2009.00425.x

Zomer, A. and Benneworth, P. (2011), “The rise of the university's third mission”, in Enders, J., de Boer, H.F. and Westerheijden, D.F. (Eds), Reform of Higher Education in Europe, Sense Publishers.

\section{Corresponding author}

Justyna Fijałkowska can be contacted at: jijjalkowska@spoleczna.pl

For instructions on how to order reprints of this article, please visit our website:

www.emeraldgrouppublishing.com/licensing/reprints.htm

Or contact us for further details: permissions@emeraldinsight.com 